\title{
COMUNICAÇÃO
}

\section{ANÁLISE DO MERCADO DE FRUTAS EM LAVRAS-MG ${ }^{1}$}

\author{
Analysis of fruit market in Lavras - MG
}

\section{Lair Victor Pereira ${ }^{2}$, Enilson Abrahão ${ }^{3}$, José Clélio de Andrade ${ }^{4}$, José Carlos Fráguas ${ }^{5}$, Ângelo Albérico Alvarenga ${ }^{5}$}

\begin{abstract}
RESUMO
Neste trabalho, objetivou-se estudar o mercado de frutas na cidade de Lavras - MG. As coletas de dados foram realizadas mensalmente nos supermercados, sacolões e feiras livres, utilizando-se de um questionário e executado em duas etapas: a primeira de julho de 2002 a junho de 2003 e a segunda de julho de 2004 a junho de 2005. Procurou-se investigar o volume de frutas comercializado, preços, perdas, procedências e consumo per capita. Os resultados mostram um aumento de 318,5 para 377,4 t/mês, representando $17 \%$ entre a $1^{\mathrm{a}}$ e a $2^{\mathrm{a}}$ etapa. Para as frutas produzidas em Lavras a variação foi de 3,07 para 4,30\%. As perdas foram de 23,8 para 27,7 t/mês e o consumo per capita de 3,98 para 4,68 Kg/habitante/mês.
\end{abstract}

Termos para indexação: Frutas, volume comercializado, preços, perdas, procedências e consumo per capita.

\begin{abstract}
This paper aimed to study the fruit market in Lavras - MG. The data were monthly obtained in supermarkets and convenience stores using a questionary in two steps: the first one was from July/2002 to June/2003 and the second was applied from July/2004 to June/2005. The volume of commercialized fruits, prices, losses, origin and percapta consumption were investigated. The results showed an increment from 318,5 to 377,4 t/month, representing $17 \%$ between the first and second phase. Considering the fruits produced in Lavras the variation was from 3,07 to $4,30 \%$. The losses ranged from 23,8 to $27,7 \mathrm{t} /$ month and the percapta consumption from 3,98 to $4,68 \mathrm{Kg} /$ habitant/month.
\end{abstract}

Index terms: Fruits, commercialized fruits, price, losses, origin and percapta consumption.

\section{(Recebido em 21 de dezembro de 2005 e aprovado em 2 de março de 2007)}

A fruticultura, de uma maneira geral, vem alcançando grande destaque no Brasil, não só pela importante alternativa de diversificação e aumento de renda para a pequena propriedade, como também pela geração de empregos por se tratar de uma atividade altamente agregadora de mão-de-obra e indutora da instalação de pólos agroindustriais.

O estado de Minas Gerais, além de sua grande extensão territorial, possui diferentes características climáticas que permitem a exploração de frutíferas que se adaptam desde climas temperados às tropicais.

O município de Lavras - MG, com sua excelente localização geográfica em relação aos grandes centros consumidores do país, vem experimentando, nos últimos 10 anos, importantes avanços na consolidação da fruticultura como uma opção vantajosa e rentável para as pequenas propriedades rurais.

Conhecer como se comporta o mercado de frutas em Lavras, origem desses frutos, volume comercializado, índice de perdas, entre outros, constitui um fator fundamental que a EPAMIG/CTSM, através de seus pesquisadores, buscou avaliar com o objetivo de incrementar as ações de incentivo, diversificação e ampliação da fruticultura na região de Lavras (FRUTILAVRAS, 1997).

A pesquisa foi realizada mensalmente nos principais sacolões, supermercados e feiras livres da cidade, incluindo estabelecimentos comerciais da periferia. A coleta dos dados foi feita mediante a aplicação de um questionário previamente elaborado, abrangendo duas etapas, sendo a

\footnotetext{
${ }^{1}$ Trabalho desenvolvido e financiado pela EPAMIG/CTSM - Lavras/MG.

${ }^{2}$ Engenheiro Agrônomo, Mestre em Fitopatologia, Pesquisador - Empresa de Pesquisa Agropecuária de Minas Gerais/EPAMIG-CTSM - Cx. P. 176 37200-000 - Lavras, MG - lair@epamig.br

${ }^{3}$ Engenheiro Agrônomo, Mestre em Fitotecnia, Pesquisador - Empresa de Pesquisa Agropecuária de Minas Gerais/EPAMIG-CTSM - Cx. P. 176 - $37200-000$ Lavras, MG - enilson@epamig.br

${ }^{4}$ Engenheiro Agrônomo, Mestre em Administração, Pesquisador - Empresa de Pesquisa Agropecuária de Minas Gerais/EPAMIG-CTSM - Cx. P. 176 37200-000 - Lavras, MG - jclelio@vialavras.com.br

${ }^{5}$ Engenheiros Agrônomos, Doutores em Fitotecnia, Pesquisadores - Empresa de Pesquisa Agropecuária de Minas Gerais/EPAMIG-CTSM - Cx. P. 176 37200-000 - Lavras, MG - jcfraguas@bol.com.br; angelo@epamig.ufla.br
} 
primeira de julho de 2002 a junho de 2003 e a segunda de julho de 2004 a junho de 2005.

Foram obtidas informações referentes ao volume comercializado de frutas, procedência, preço pago pelo consumidor e porcentagem de perdas.

Conforme dados apresentados na Tabela 1, na primeira etapa (julho/2002 a junho/2003), o mercado de frutas do município de Lavras comercializou, em média, 318,5 toneladas de frutas/mês, movimentando recursos financeiros da ordem de R $\$ 455 \mathrm{mil} / \mathrm{mês}$, com um preço médio de $\mathrm{R} \$ 1,43$ o quilograma de fruta .

Já, na segunda etapa de coleta de dados (julho/ 2004 a junho/2005), o volume médio de frutas comercializado foi de 374,4 t/mês, representando uma movimentação financeira mensal de aproximadamente $\mathrm{R} \$ 573 \mathrm{mil}$, com um preço médio de $\mathrm{R} \$ 1,53$ por quilograma de fruta, Tabela 1 . Observa-se então na segunda etapa, um incremento de $17,5 \%$ no volume comercializado e de $25,9 \%$ no valor recebido para um aumento de apenas 7,0\% no preço médio/ $\mathrm{Kg}$ pago pelo consumidor.

Seguindo uma tendência mundial relativa ao aumento do consumo de frutas pela população, motivada principalmente pelos aspectos relacionados à saúde $\mathrm{e}$ melhor qualidade de vida, pode-se dizer que, em Lavras, essa linha também se manteve. No período 2004/2005 houve um incremento de mais de $17 \%$ no volume comercializado de frutas, com um aumento de quase $26 \%$ nos valores financeiros movimentados, em relação ao período 2002/ 2003 (ALVARENGA et al., 2004; ANDRADE et al., 2003).

Na produção e comercialização de frutas, aspectos relacionados a perdas são de fundamental importância, constituindo um segmento que tem merecido estudos e investigações freqüentes por parte da pesquisa, envolvendo alguns itens como colheita, embalagem, transporte, armazenamento e tratamentos pós-colheita.

No comércio de frutas praticado em Lavras constatou - se , nos dois períodos de avaliação, uma perda média da ordem de 23,8 toneladas de frutas/mês na primeira etapa e de 27,4 toneladas de frutas/mês na segunda etapa. Estes dados representam $7,3 \%$ e $7,4 \%$ dos volumes comercializados, respectivamente. Essas perdas são atribuídas, em parte, a forma de exposição das frutas nas bancas, o que propicia o seu manuseio pelos consumidores. Pesquisa realizada junto ao setor supermercadista, mostra que nos estados de Minas Gerais e do Rio de Janeiro, 92\% e $98 \%$ dos consumidores de frutas, respectivamente, preferem comprar a granel, ou seja, querem manusear o produto antes de comprá-lo (FRUTIFATOS, 2003).

Tabela 1 - Quantidade de frutas comercializadas no município de Lavras - MG ,valor (e perdas), nas etapas de julho/ 2002 a junho/2003 e julho/2004 a junho/2005.

\begin{tabular}{lcccccc}
\hline \multirow{2}{*}{ Mês } & \multicolumn{7}{c}{ Etapas } \\
\cline { 2 - 7 } & \multicolumn{7}{c}{$2002 / 2003$} & & $2004 / 2005$ & Perdas \\
\cline { 2 - 6 } & Qtde & Valor & Perdas & Qtde & Valor & (t) \\
\hline Julho & 292,1 & 343,24 & 21,9 & 393,2 & 492,10 & 26,8 \\
Agosto & 312,3 & 422,36 & 23,4 & 385,9 & 581,40 & 28,0 \\
Setembro & 309,6 & 377,98 & 23,2 & 383,0 & 590,90 & 28,1 \\
Outubro & 330,9 & 452,73 & 24,8 & 350,9 & 529,30 & 26,7 \\
Novembro & 356,4 & 556,72 & 26,9 & 355,0 & 606,60 & 28,3 \\
Dezembro & 372,1 & 577,08 & 27,9 & 401,1 & 625,50 & 26,5 \\
Janeiro & 282,5 & 435,98 & 21,1 & 389,7 & 618,50 & 27,5 \\
Fevereiro & 298,1 & 418,54 & 21,9 & 396,9 & 668,70 & 27,3 \\
Março & 311,4 & 495,36 & 23,3 & 344,2 & 537,50 & 27,8 \\
Abril & 322,6 & 494,76 & 24,2 & 382,4 & 548,26 & 27,0 \\
Maio & 352,8 & 445,90 & 26,5 & 354,5 & 542,30 & 28,0 \\
Junho & 281,9 & 445,54 & 21,1 & 366,3 & 546,90 & 26,8 \\
Total & $3.922,7$ & $5.466,43$ & ------ & $4.493,1$ & $6.887,96$ & ----- \\
\hline Média & 318,5 & 455,51 & 23,8 & 374,4 & 573,50 & 27,4 \\
\hline
\end{tabular}

Ciênc. agrotec., Lavras, v. 32, n. 6, p. 1981-1984, nov./dez., 2008 
Com relação à origem das frutas comercializadas em Lavras, constatou-se que a CEASA-MG e CEAGESP são as duas maiores fontes de abastecimento, representando no período de 2002/03 cerca de 51,44\% e 45,49\%, respectivamente (Tabela 2 ). A região de Lavras participou apenas com 3,07\%, tendo maior participação nos meses de março, abril, maio, junho ,julho e agosto, justamente quando existe uma grande oferta de tangerina 'Ponkan' e goiaba, oriundas de plantios comerciais já em produção no município e região, uma vez que a banana, outra fruta de grande importância local, é comercializada praticamente o ano todo.

Nas avaliações realizadas no período de 2004/05 (Tabela 2), esta situação praticamente não se alterou, permanecendo valores da ordem de 51,51\% e 44,19\% de frutas, provenientes da CEASA-MG e CEAGESP, respectivamente.

No entanto, nesse período houve um aumento significativo em relação à participação das frutas provenientes de Lavras e região, chegando a 4,30\%. Este valor representou um incremento de mais de $40 \%$ em comparação com o mesmo período de 2002/2003.

Considerando o município de Lavras com aproximadamente 80 mil habitantes, verifica-se um consumo per capita de frutas da ordem de 3,98 Kg/habitante/mês para o período 2002/03. Nas avaliações realizadas no período 2004/05, esse valor subiu para 4,68 Kg/habitante/ mês. Esses dados projetam um consumo anual de 47,76 $\mathrm{Kg} /$ habitante e $56,16 \mathrm{Kg} /$ habitante, respectivamente. São valores extremamente baixos se comparados com dados da Organização das Nações Unidas para Agricultura e
Alimentação (FAO), que registram 62,40 Kg/hab./ano no mundo, também considerado baixo. No Brasil esse valor é da ordem de $57,00 \mathrm{Kg} / \mathrm{hab}$./ano, enquanto na Itália e Espanha, o consumo per capita é de 114,00 Kg/hab./ano e $120,00 \mathrm{Kg} / \mathrm{hab} . / \mathrm{ano}$, respectivamente.

Em função do volume de frutas demandado mensalmente e das inúmeras vantagens comparativas e competitivas do município de Lavras, pode-se concluir que a implementação da atividade frutícola como fonte geradora de emprego e renda deve ser cada vez mais incentivada. Esse consumo mensal de frutas permite projetar um volume de, aproximadamente 4.500 toneladas/ano, conforme Tabela 1, o que equivale a uma ampliação da área frutícola em mais ou menos 300 hectares, gerando cerca de 900 empregos diretos no campo, proporcionando a movimentação de mais de 4 milhões de reais na economia local.

Neste contexto, o Programa para Desenvolvimento da Fruticultura no Município de Lavras - FRUTILAVRAS, criado em 1995 através da força da parceria de diferentes instituições, mostra o nível de acerto dos organizadores em apostar na fruticultura como uma grande alternativa para as pequenas propriedades rurais.

Hoje, a fruticultura já existe em escala comercial na região de Lavras. Frutas como maracujá, goiaba, uva, pêssego, ameixa, atemóia, banana e figo são amplamente produzidas e comercializadas. A criação da Associação de Fruticultores de Lavras, estimulou a produção e diversificação dessas frutas, culminando com a implantação de uma agroindústria apta a produzir polpas e doces, agregando valores nos produtos.

Tabela 2 - Procedências das frutas comercializadas no município de Lavras - MG nas etapas de julho/2002 a junho/ 2003 e julho/2004 a junho de 2005.

\begin{tabular}{lcccccc}
\hline \multirow{2}{*}{ Mês } & \multicolumn{3}{c}{ 2002/2003 $(\%)$} & \multicolumn{3}{c}{ 2004/2005 (\%) } \\
\cline { 2 - 6 } & CEASA-MG & CEAGESP & Lavras & CEASA-MG & CEAGESP & Lavras \\
\hline Julho & 57,46 & 36,57 & 5,97 & 55,78 & 40,00 & 4,22 \\
Agosto & 68,55 & 29,71 & 1,97 & 60,30 & 35,30 & 4,40 \\
Setembro & 51,63 & 46,63 & 1,74 & 55,60 & 42,30 & 2,10 \\
Outubro & 54,17 & 44,18 & 1,65 & 55,20 & 42,20 & 2,60 \\
Novembro & 58,30 & 40,51 & 1,19 & 59,30 & 38,70 & 2,00 \\
Dezembro & 43,31 & 55,56 & 1,13 & 40,70 & 56,30 & 3,00 \\
Janeiro & 40,43 & 58,34 & 1,23 & 40,70 & 56,30 & 3,00 \\
Fevereiro & 51,63 & 46,53 & 1,84 & 49,58 & 47,70 & 2,72 \\
Março & 50,69 & 44,95 & 4,36 & 49,78 & 43,80 & 6,42 \\
Abril & 52,67 & 43,09 & 4,24 & 50,72 & 42,40 & 6,88 \\
Maio & 42,99 & 50,89 & 6,12 & 50,50 & 42,50 & 7,00 \\
Junho & 45,50 & 48,93 & 5,57 & 50,00 & 42,80 & 7,20 \\
\hline Média & 51,44 & 45,49 & 3,07 & 51,51 & 44,19 & 4,30 \\
\hline
\end{tabular}




\section{REFERÊNCIAS BIBLIOGRÁFICAS}

ALVARENGA, A. A.; ABRAHÃO, E.; FRÁGUAS, J. C.; ANDRADE, J. C. de; PEREIRA, L. V. Mercado de frutas em Lavras, MG. In: CONGRESSO BRASILEIRO DE FRUTICULTURA, 18., 2004, Florianópolis. Anais... Florianópolis: UFSC, 2004. CD-ROM.

ANDRADE, J. C. de; PEREIRA, L. V.; SANTOS, C. C. dos; FRÁGUAS, J. C.; ABRAHÃO, E.; ALVARENGA, A. A.
Mercado de frutas em Lavras, MG. Lavras: Epamig/CTSM, 2003. 4 p. (Circular técnica, 161).

FRUTIFATOS. A supremacia do granel: $98 \%$ preferem esta forma de aquisição. Brasília, DF: Ministério da Integração Nacional, 2003.

FRUTILAVRAS. A fruticultura como alternativa de renda para o município de Lavras. Informe Agropecuário, Belo Horizonte, v. 18, n. 188, p. 57-60, 1997. 